\title{
REDES DE PODER E ESTRATÉGIAS ESPACIAIS DOS FISCAIS MUNICIPAIS EM SANT'ANA DO LIVRAMENTO (RS)
}

\author{
ADRIANA DORFMAN ${ }^{1}$ \\ ARTHUR BORBA COLEN FRANÇA ${ }^{2}$ \\ GUILHERME SOARES ${ }^{3}$ \\ ROBERTA CORSEUIL DURAN ${ }^{4}$ \\ Universidade Federal do Rio Grande do Sul
}

Resumo: O trabalho discute estratégias espaciais dos fiscais municipais para controlar o escoamento da produção de arroz no interior do município de Sant'Ana do Livramento, no estado do Rio Grande do Sul, Brasil. As implicações da proximidade física e social dos fiscais municipais, em suas características de funcionários e moradores do lugar, se explicitam num posto de controle de guias de produção para a arrecadação do ICMS. A análise do poder em rede na escala local do Estado, ligando seus empregados aos produtores agrícolas e aos moradores de Livramento, se fez através da observação participante da fiscalização em campo no verão de 2012. Apresentamos um mapa dos locais escolhidos para a instalação dos acampamentos sazonais, descrevemos a organização do controle e discutimos as estratégias espaciais com base em diferentes informantes e na teorização sobre territorialidade humana - desenvolvida por Robert Sack (1986). Por fim, organizamos as relações segundo escalas geográficas. Concluiu-se que os fiscais municipais - uma ramificação de poder (estatal) na esfera municipal - mantêm relações marcadas pela pessoalidade, podendo-se também notar que os agentes - fiscais de diferentes graus hierárquicos e pertinências institucionais, produtores rurais, caminhoneiros, habitantes do lugar - situam-se em mais de uma posição na rede de poder. Conclui-se ainda que a ação dos fiscais se liga ao conteúdo das relações, isto é, à

${ }^{1}$ Doutora em Geografia, professora do Departamento de Geografia e do Programa de PósGraduação em Geografia da UFRGS. Contato: adriana.dorfman@ufrgs.br.

${ }^{2}$ Graduando em Relações Internacionais na UFRGS. Contato: arthurborba@outlook.com.

${ }^{3}$ Graduando em Ciências Sociais na UFRGS. Contato: guimsoares@ gmail.com.

${ }^{4}$ Graduanda em Geografia na UFRGS, professora da rede municipal em Porto Alegre. Contato: robertad@portoweb.com.br. 
disposição de poderes e à identificação com os interesses dos agentes nas diferentes escalas geográficas.

Palavras-chave: Redes de Poder; Fiscalização tributária; Estratégias espaciais; Sant'Ana do Livramento.

\section{POWER NETWORKS AND SPATIAL STRATEGIES OF THE MUNICIPAL TAX CONTROLLERS IN SANT'ANA DO LIVRAMENTO (RS)}

Abstract: The paper discusses spatial strategies of municipal tax controllers to control the flow of rice production within the municipality of Sant'Ana do Livramento (RS-Brazil). The implications of physical proximity and social development of municipal tax controllers on their characteristics of municipal officials and residents were made explicit in a checkpoint for the collection of VAT. The analysis of the power network at local state connecting employees to farmers and residents of Livramentowas made through participant observation of inspectors in the field in the summer of 2012. We presented a map of the locations chosen for the installation of seasonal camps and we described the organization of control. We also discussed the spatial strategies based on different informants and theorization about human territoriality developed by Robert Sack (1986). Finally, we organized the relations according to geographical scales. It was concluded that municipal tax controllers - a branch of power (state) at the municipal level - maintain relationships marked by personality, and you can also notice that the players - of different degrees of fiscal, hierarchical and institutional pertinence (farmers, truckers, and residents of place) - are located in more than one position in the power network. We can also conclude that the action of tax controllers binds to the content of relations, i.e., the provision of power and identification with the interests of agents in different geographical scales.

Keywords: Power Networks; Spatial Strategies; Tax Control; Sant'Ana do Livramento.

\section{Introdução}

Este artigo se insere na pesquisa Contrabando na fronteira Sul: territorialização das modalidades tradicionais e emergentes - financiado pelo Conselho Nacional de Desenvolvimento Científico e Tecnológico, CNPq -, ainda que aborde um tema paralelo. Durante a realização de um trabalho de campo no final de 2011, em Santana do Livramento, RS, cidade fronteiriça com o Uruguai, foram contatados funcionários 
municipais que relataram, inicialmente, que o contrabando não era uma preocupação nem uma ocupação de seu cotidiano. Nas palavras de um deles:

Fiscal A: Se, porventura, passa numa barreira um ilícito desse padrão aí encaminhamos, mas a gente não sai com a finalidade de procurar e encontrar tráfico de drogas, é óbvio. Não procuramos, isso é problema da Polícia Civil, Polícia Federal, Brigada, polícia ostensiva... nós não somos da polícia, mas se a gente estiver numa barreira e por alguma infelicidade revisar um carro $\mathrm{e}$ achar, vai se dar o encaminhamento. Claro que vai, mas a finalidade nossa não é essa, porque não é da nossa competência. Isso é segurança pública (Entrevista em 20/12/2011 na Secretaria da Fazenda de Sant'Ana do Livramento, grifo nosso).

Mesmo sem tratar do trânsito aduaneiro, as reflexões dos fiscais sobre sua atuação no controle do trânsito local de mercadorias mostraramse muito relevantes para o entendimento das estratégias ligadas à fiscalização do espaço próximo. Assim, realizaram-se quatro trabalhos de campo no verão de 2011-2012 tendo como objeto de pesquisa os fiscais municipais e suas relações rotineiras de trabalho.

Conhecer os diferentes lugares de trabalho e o modo como se dá a colaboração entre funcionários públicos e moradores do lugar; e discutir com eles as formas e a importância do controle tributário foram algumas das atividades realizadas em campo. $\mathrm{O}$ acompanhamento das barreiras de fiscalização das notas fiscais emitidas pelos produtores rurais sempre que promovem saídas de mercadorias -, e que permitem arrecadar o Imposto de Circulação de Mercadorias e Serviços (ICMS) - imposto cobrado pelos municípios e depositado nos cofres estaduais - no escoamento da safra 2011-2012 de arroz, constituiu-se enquanto tema central dos contatos.

Deve-se pontuar o parentesco de um dos pesquisadores com o secretário municipal, superior hierárquico dos fiscais. Se por um lado esse vínculo facilitou o primeiro contato com o objeto de pesquisa e com os informantes, por outro, a relação de subordinação e possivelmente, certa desconfiança, marcou o início das relações entre pesquisadores e pesquisados. Esse estranhamento arrefeceu a partir do convívio e um vínculo de confiança entre os fiscais e os pesquisadores foi sendo criado na medida em que deixamos claro que se tratava de um trabalho acadêmico, que não tínhamos nenhuma intenção de policiar ou julgar sua forma de 
trabalho. Ainda assim, podemos perceber que os fiscais desenvolveram o entendimento de que o presente trabalho é uma forma de reconhecimento do serviço prestado ao município. Por fím, notou-se que eles viam no registro de suas dificuldades um canal de reivindicação, de busca de melhorias e maior prestígio junto ao poder executivo.

Em termos disciplinares a Geografia, a Antropologia e as Relações Internacionais contribuíram com método, técnica e teoria, permitindo a discussão sobre a territorialidade e as estratégias espaciais de controle tributário através da observação participante. A contribuição teórica da Geografia está em estabelecer um marco teórico e metodológico para a discussão, a partir das propostas de sistema territorial e territorialidade humana (RAFFESTIN, 1993; SACK, 1986) e da metodologia escalar (RACINE, RAFFESTIN e RUFFY, 1983; DORFMAN, 1992; SMART e LIN, 2014). Entre as técnicas, nos propusemos a cartografar a produção de arroz e as rotas de seu escoamento, relacionando-as à implantação das barreiras para o controle do ICMS.

O olhar antropológico possibilitou (através da inserção no lugar) uma maior aproximação com os agentes sociais envolvidos. A convivência cotidiana no grupo de fiscais permitiu naturalizar o estranhamento dos primeiros contatos, e dar a ver as práticas usuais (linguajar, forma de abordagem dos caminhões e até mesmo brincadeiras) que poderiam estar desautorizadas por nossa presença. O antropólogo Roberto DaMatta defende as seguintes tarefas: transformar o exótico em familiar e o familiar em exótico (1978). Dessa forma, a aproximação e o distanciamento contribuíram na compreensão das vivências de campo.

Um olhar para o Estado em comparação ao olhar particularizado para as redes e relações de poder e a fronteira como palco de suas materializações são contribuições do encontro entre as teorias das Relações Internacionais e as práticas de controle de circulação de mercadorias. De certa maneira, trata-se uma manifestação da "fronteira como método" proposta por Sandro Mezzadra e Brett Neilson (2008), que explicitam:

Entendemos que o método emerge precisamente das circunstâncias materiais presentes, que, no caso das fronteiras, são aquelas de tensão e conflito, partição e conexão, passagem e barreira, vida e morte. A fronteira como método, portanto, implica não apenas numa perspectiva epistêmica a partir da qual toda uma série de conceitos estratégicos, bem como de relações de fronteira, podem ser reformuladas. Ela 
também requer um processo de pesquisa que continuamente considera e reage às múltiplas batalhas e negociações (...) que constituem a fronteira como uma instituição e um conjunto de relações sociais (p. 1, t.n.).

\section{O espaço}

Para melhor compreensão do objeto aqui abordado, cabe apresentar o contexto econômico e social da região da fronteira gaúcha onde se insere Sant'Ana do Livramento. As cidades que pontilham a 'linha' ou 'línea', como é localmente conhecida a fronteira entre o Brasil e o Uruguai, são de tal maneira integradas que foram descritas por Raymond Pébayle como "bicéfalas do ponto de vista administrativo, mas perfeitamente complementares do ponto de vista econômico" (1978, p.40). Na literatura sobre a região, é usual a expressão cidades-gêmeas, mas Gisela Copstein afirma que Sant'Ana do Livramento-Rivera é uma única cidade, sujeita a duas soberanias (1989). Trata-se, de qualquer forma, de um conjunto urbano com uma hinterlândia comercial que chega, para certas atividades econômicas, à Montevidéu e Porto Alegre.

Além disso, deve-se considerar que para cidades periféricas nos confins do Cone Sul, Livramento-Rivera podem ser consideradas francamente cosmopolitas, pelo menos desde meados da década de 1950. $\mathrm{E}$, como ocorre em muitas cidades de fronteira, ambas as cidades estão pontilhadas de órgãos de controle federais com grandes prédios e contingente destinado ao governo dos trânsitos fronteiriços. Desde a instauração do MERCOSUL, algumas dessas funções administrativas das cidades-gêmeas se transnacionalizaram no posto de fiscalização sanitária, no porto seco, etc. O comércio local e os serviços de educação e saúde também se organizam considerando a condição fronteiriça (DORFMAN, 2007).

No caso de Sant'Ana do Livramento, as atividades primárias têm relevância econômica e simbólica, predominando a pecuária e a agricultura - que se concentra no plantio de arroz e soja. Também essa produção é fortemente internacionalizada, uma vez que há muitos brasileiros com terras no Uruguai, empregando mão-de-obra brasileira - frequentemente em condições irregulares - e exportando via Montevidéu, ou beneficiando e internando o arroz no mercado brasileiro. 
No entanto, o tema aqui abordado - a gestão da arrecadação do ICMS - apesar de passados mais de 20 anos de MERCOSUL, mostra como os territórios estatais mantêm diferenciações. $\mathrm{O}$ imposto gerado pelo município é recolhido pela Secretaria da Fazenda Estadual - no caso, do RS - que devolverá $1 / 4$ do total aos municípios, considerando um índice de participação formado pelo montante recolhido, o número de habitantes, o índice de evasão escolar, mortalidade infantil, entre outros fatores.

É nesse contexto que o município se mobiliza para aumentar a arrecadação através da fiscalização ostensiva no período de escoamento da safra de arroz e soja, entre fim de fevereiro e meados de junho dependendo do comportamento climático e dos preços no mercado internacional. Afinal, o retorno do ICMS é uma das maiores fontes de recursos para o município. O pessoal disponível na prefeitura é deslocado da área urbana, estabelecendo postos de controle tributário na forma de barreiras nas estradas que ligam as áreas produtoras e os mercados.

\section{As estratégias de controle espacial por barreira}

No processo de construção do Estado territorial, a primeira função das fronteiras foi construir barreiras tributárias estatais. Organizações políticas anteriores como impérios ou feudos organizados em suserania e vassalagem também se baseavam na tributação das unidades políticas periféricas, oferecendo proteção como contrapartida. A construção do Estado territorial, no entanto, significou a unificação de vários aspectos antes descentralizados, como a economia, o aparelho administrativo etc. Dentre os quais, destacamos a construção de barreiras não tarifárias (ALLIÈS, 1980). O controle dos fluxos de pessoas e mercadorias barrando-as ou taxando-as - é essencial para a elaboração de uma dicotomia entre externo e interno, cerne dessa nova organização política, representada pelo limite interestado. Os limites do território estatal e as barreiras não tarifárias que demarcam o mercado nacional passam a coincidir e a se confundir.

Já a barreira tributária vincula-se à legalidade e não à distinção entre interno/externo, como é o caso do limite e da barreira não tarifária. Em outras palavras, a barreira tributária é a manifestação espacial do controle tributário. É preciso deixar clara, assim, a diferença entre barreira não tarifária estatal e barreira tributária. A primeira é uma norma que abrange todo o território estatal, enquanto a barreira tributária é um objeto concreto 
cujo propósito é controlar a taxação de mercadorias em fluxo através de certos pontos do território. Este texto trata das barreiras tributárias fixas estabelecidas nas vias de escoamento do arroz no município de Sant'Ana do Livramento, cujo propósito é legalizar as guias do produtor rural para a entrada do produto no mercado nacional. Essa legalização se dá pelo carimbo dos papéis, a fim de tornar inviável sua reutilização e, portanto, a sonegação de tributos (ver Figura 1).

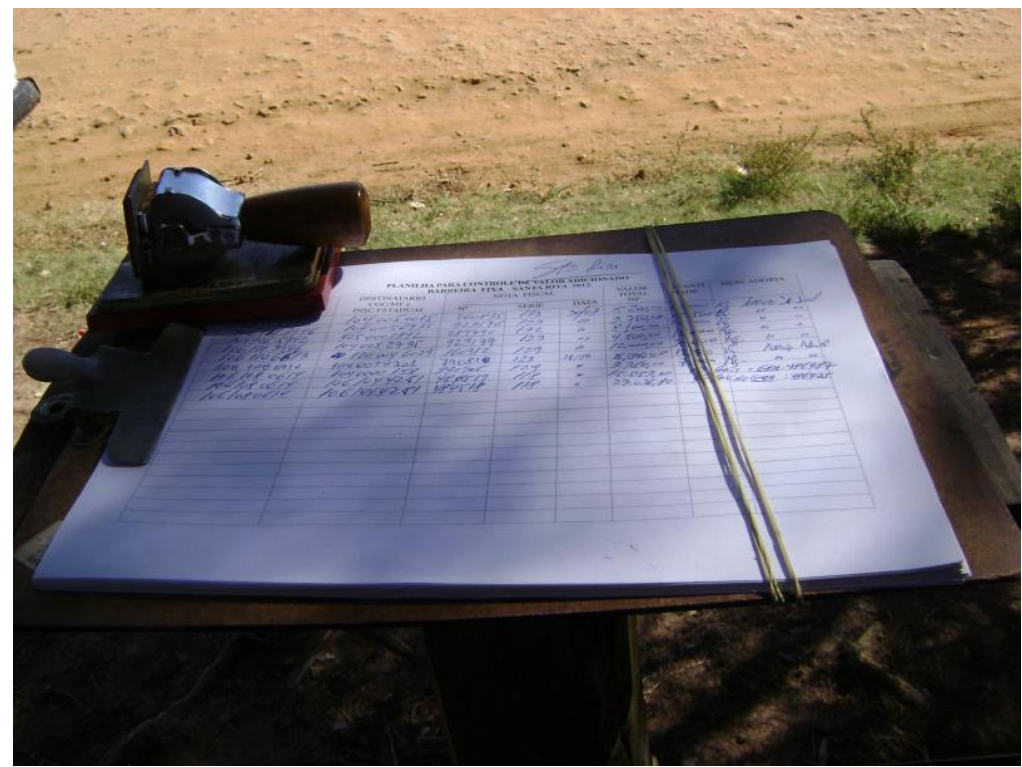

Figura 1: Carimbo e planilha de controle das guias do produtor rural na barreira de Santa Rita, Sant'Ana do Livramento (RS), 31/03/2012. Foto: Guilherme Soares.

Faz-se necessário observar que a estratégia espacial de barreira se manifesta de formas que não necessariamente coincidem com essa empregada pelos fiscais de Sant'Ana do Livramento. Além da barreira fiscal ou fixa, há a barreira ostensiva. As diferentes estratégias são relatadas criticamente por um fiscal municipal:

Fiscal A: Essa barreira do Exército, eu acho um crime fazer isso. Sete dias no mesmo lugar, pra finalidade que eles querem... a nossa é diferente. A nossa barreira é alfandegária, 
visa pegar o produtor rural com a safra. Ele não tem como passar por outro lugar a não ser por ali. A senhora sabe que a sonegação existe, chega a $1 / 3$ da safra, mais que isso eles não sonegam porque aí fica complicado junto à Receita Federal. Mas no caso de uma barreira do Exército, vamos colocar essa que está começando agora, aqui, quem vai para o Caxeiral. Três ou quatro vezes que eu passei ali, eles faziam cinco dias que eles estavam ali. Não funciona. Meia hora depois que eles instalaram a barreira, eu, que não tenho problema nenhum com o Exército, já sei que a barreira está lá. A senhora imagina o ilícito, ele vai passar lá? É claro que não. A barreira que funciona é a barreira relâmpago. Pega um urutu daqueles e bota dez homens ali dentro e sai com um oficial ou um sargento. Estaciona aqui, fica uma hora e meia, depois vai pra outro lugar. Aí pega. Barreira fixa não pega ninguém. (Entrevista em 20/12/2012 na SEFAZ de Livramento).

Deve-se considerar que a barreira montada durante as operações do Exército tem primariamente a função de demonstrar pedagogicamente a presença do contingente militar, do Estado em suas margens. A barreira ostensiva tem sido usada pela Polícia Federal, Polícia Rodoviária Federal, Polícia Militar, Polícia Civil e pelo Exército Brasileiro em operações e barreiras com a finalidade de "criar o risco" em "policiamento ostensivo" (DORFMAN, PRYTOLUK e SEBASTIÃO, 2011). Não se trata de uma barreira fixa, portanto.

Outros informantes mencionam obstáculos que se materializam em barreiras ditas "estratégicas" ou "cirúrgicas", que não estão baseadas em controlar permanentemente um determinado ponto por onde passarão fluxos conhecidos, mas em surpreender e reprimir um fluxo que provavelmente passará por determinado ponto, conforme indicam investigações e operações de inteligência prévias. Essa estratégia é empregada pela Polícia Federal e pela Receita Federal do Brasil, como pode ser visto nos trechos que se seguem. Em entrevista realizada na data de 30/11/2011, na sede em Porto Alegre, um delegado da Polícia Federal explana:

A Polícia Federal tem o trabalho dela, né, o mesmo trabalho que ela faz nos portos, nas regiões de fronteira, ela faz nos portos, nos aeroportos. É trabalho de investigação. Se a gente recebe uma informação a gente trabalha, descobre, pra 
descobrir se tem algum esquema de contrabando. A gente faz em porto, aeroporto. O trabalho da Polícia é um trabalho de inteligência. A gente trabalha pra combater as organizações criminosas. Basicamente é o que a gente faz, não é? É... Este trabalho de repressão pura e simples, não é. De ficar ali parado, fazendo barreira, esse é o trabalho de outras instituições. Não é da Polícia Federal. A gente é uma polícia de investigação.

Já um auditor da Receita Federal do Brasil, afirma que o órgão emprega barreiras ostensivas para orientar os turistas e barreiras cirúrgicas para flagrar contrabandistas de monta:

(...) atua de forma cirúrgica. Não faz barreiras na rodovia. Através das investigações, atua diretamente onde há forte indício de contrabando. É necessário separar contrabandista de turista. É outro perfil, embora algumas vezes o turista cometa descaminho. O turista pode se colocar em situações de risco ao optar por estradas vicinais, pensando estar irregular, expondo-se a risco de ataques de assaltantes de cargas. As unidades de fronteira têm barreiras constantemente e também agem estrategicamente. (Entrevista em 10/10/2010 na sede da $10^{\mathrm{a}}$ Região Fiscal da Receita Federal do Brasil, Porto Alegre).

Assim, a pluralidade de configurações da barreira - que assume as formas fixa, ostensiva e cirúrgica - corresponde a estratégias espaciais diferenciadas por parte dos órgãos repressores e dos agentes a serem controlados. E para melhor compreender a barreira tributária em questão, recorremos às teorias sobre territorialidade. Como afirma Robert David Sack (1986), uma das funções da territorialidade é o controle da legalidade (ver Figura 2). 


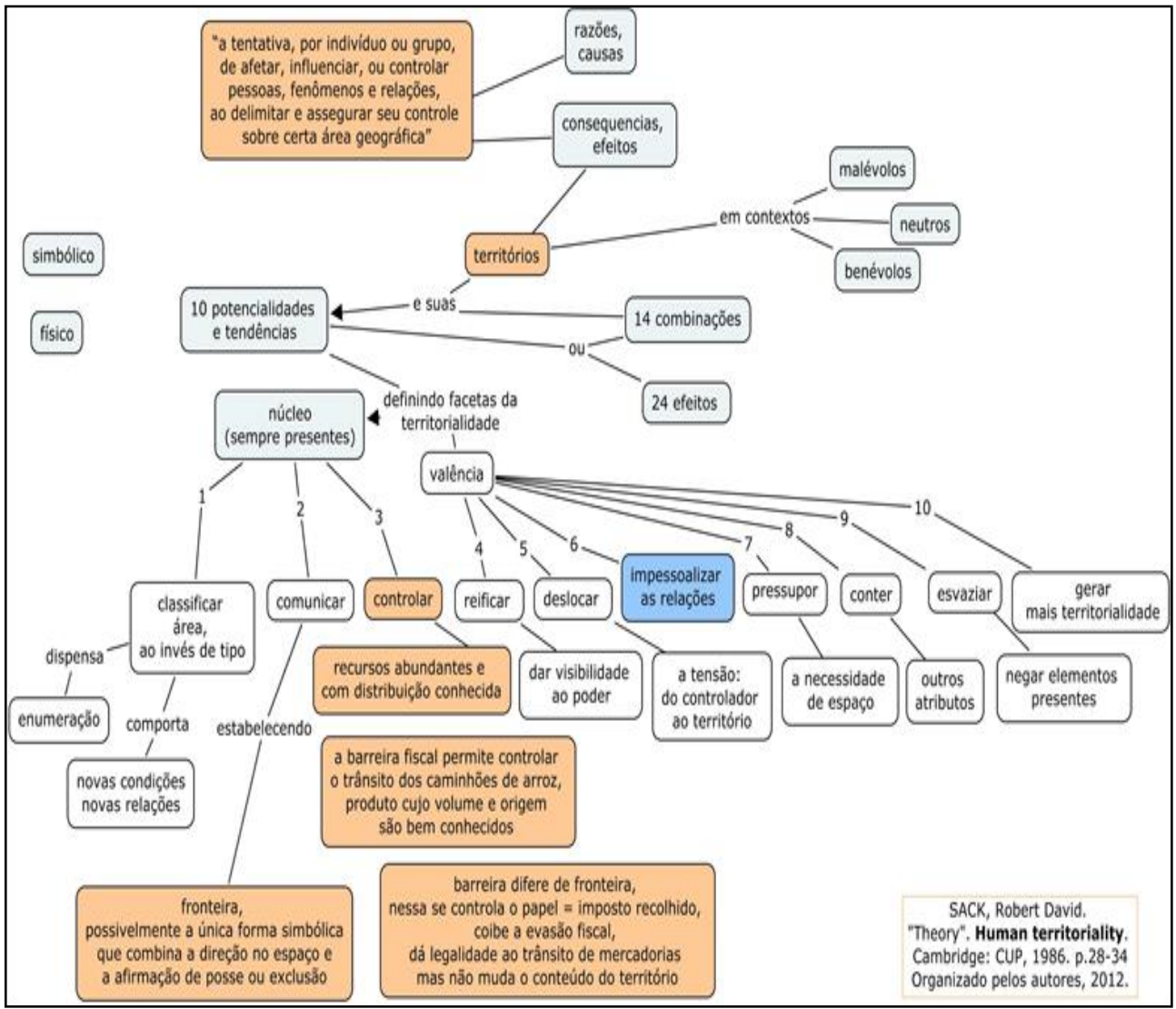

Figura 2: Mapa conceitual da teoria sobre a territorialidade humana de R.D.Sack.

Elaborado por Adriana Dorfman e Arthur Borba Colen França, 2012.

As estratégias espaciais sempre traduzem relações sociais. Por vezes, as relações sociais se naturalizam por meio de sua expressão no espaço, metaforizando-se nele. Por outras, como é o caso da barreira - territorial por estratégia -, é a existência material que está na base das relações, é o que as organiza (ver Figura 3). 


\begin{tabular}{|c|c|}
\hline $\begin{array}{l}\text { Estratégias } \\
\text { espaciais }\end{array}$ & $\begin{array}{c}\text { Facetas da territorialidade, segundo Robert } \\
\text { D.Sack (1986) }\end{array}$ \\
\hline Limite & $\begin{array}{l}\text { Classificar, comunicar, controlar, reificar deslocar, } \\
\text { conter, esvaziar e gerar mais territorialidades }\end{array}$ \\
\hline Fronteira & 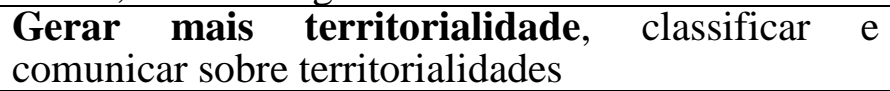 \\
\hline $\begin{array}{l}\text { Barreira } \\
\text { ostensiva }\end{array}$ & $\begin{array}{l}\text { Comunicar, gerar, reificar, impessoalizar, esvaziar } \\
\text { e controlar territorialidades }\end{array}$ \\
\hline $\begin{array}{l}\text { Barreira } \\
\text { cirúrgica }\end{array}$ & Controlar territorialidades \\
\hline Barreira fixa & $\begin{array}{l}\text { Controlar, comunicar, reificar, impessoalizar e } \\
\text { gerar mais territorialidade }\end{array}$ \\
\hline
\end{tabular}

Figura 3: Tabela - síntese das facetas da territorialidade em algumas estratégias espaciais.

Elaborada por Adriana Dorfman e Arthur Borba Colen França, 2012.

Nos esquemas explicitados nas figuras 2 e 3 , que sintetizam a teoria de Sack e a empregam nas estratégias espaciais aqui discutidas, vemos, em salmão, uma das principais potencialidades ou tendências da territorialidade, a de controlar recursos abundantes e de distribuição conhecida através de barreiras fixas. Esse é o caso do arroz plantado em Sant'Ana do Livramento. As barreiras fixas servem também para comunicar normas (como a cobrança de impostos pelo Estado, neste caso, o ICMS) e reificar o poder dos grupos que controlam o território e acabam por gerar mais territorialidade.

Observe-se outra função exercida pela barreira fixa na territorialidade humana, dentro da teoria de Sack: a impessoalização das relações. A autoridade, o pertencimento, a hierarquia e a dominação se distribuem e se legitimam descolando-se das relações entre sujeitos, como efeito da classificação de objetos por área. Desta forma, um fiscal receberá do município a jurisdição, a responsabilidade e a incumbência de representálo no controle do trânsito de mercadorias. Cabe notar que, a impessoalização que diz respeito ao poder do Estado sobre o território oblitera a percepção dos agentes que realizam seus projetos por meio da construção das instituições (entre as quais, o Estado) e dos territórios (por exemplo, aquele do Estado moderno).

Se uma das estratégias espaciais do Estado para a construção e o controle do mercado nacional é a barreira tarifária e alfandegária (quando 
se trata do trânsito internacional) - em pontos de entrada e saída e ao longo das fronteiras - qual é o papel dos fiscais que, em barreiras instaladas em caminhos no interior do território estatal, controlam o escoamento da produção de arroz? Como essa teoria se traduz na prática?

\section{As barreiras fixas em Livramento}

A arrecadação de impostos por um município pode ser feita de várias formas, uma das quais é executada pelos fiscais da SEFAZ de Livramento controlando o ICMS. Durante o escoamento da safra os fiscais municipais são deslocados, alternadamente, do perímetro urbano para o perímetro rural, com o objetivo de controlar o escoamento de arroz e soja de todo o município.

Para acompanhar e legalizar a colheita, o município monta duas barreiras tributárias em estradas que dão acesso às lavouras. Os locais escolhidos são estratégicos, situando-se na convergência nas estradas de escoamento da produção e de grande fluxo dos caminhões. A escolha do local evidencia-se nas falas abaixo:

Fiscal A: Isso foi em $97 \ldots$

Fiscal B: ...O estado [o RS] né, fez esse convênio né, de trabalhar na parte de ICM. E aí a gente trabalhando aqui, pesquisando e vendo e sabendo, porque a gente é daqui né. ... onde tem maior fluxo né. E aí a gente montou. O certo seria em três pontos aqui, né. Seria lá em Santa Rita, na parada Guerra, que sai muito arroz também, e lá no Upamaroti. Só que a gente não tem como cobrir essas três. E essa na parada Guerra seria esporadicamente um cara ir ali, tirar uma manhã ali. Mas aí tu vai ficar ao relento, ficar no sol ali, vai ficar... na beira da estrada. (Entrevista em 30/03/2012 na SEFAZ de Livramento).

As características desses nós de rede são: estradas vicinais (chamadas localmente de corredores - em oposição ao controle das rodovias federais, ditas faixas [de asfalto], de alçada de outros órgãos de controle) e pontos elevados, oferecendo boa visibilidade do terreno. São estradas de chão, implicando trânsito mais lento dos grandes caminhões. Assim, reúnem três qualidades: as características do sítio (sombra, perto de casas), da situação (no alto, permitindo uma visão panorâmica; em estradas de chão, onde o 
trânsito desacelera) e da condição (elementos institucionais como a jurisdição municipal sobre os corredores).

Uma barreira fica próxima à vila Santa Rita, aproximadamente a 80 $\mathrm{km}$ da zona urbana de Livramento. Outra barreira é montada no local conhecido como Três Vendas, próxima à ponte do rio Upamaroti, na divisa entre Sant'Ana do Livramento e o município de D. Pedrito. Em cada barreira os fiscais são separados em duas equipes que contam com três membros cada uma. Seu objetivo é vigiar a estrada $24 \mathrm{~h}$ por dia durante uma semana inteira. Após uma semana ocorre a troca de turmas, realizada sempre aos sábados pela manhã. A Figura 4 mostra a localização das estradas, barreiras e áreas produtoras de arroz e soja, indicando sua posição entre a área produtora e o mercado a que se destina a mercadoria controlada. 


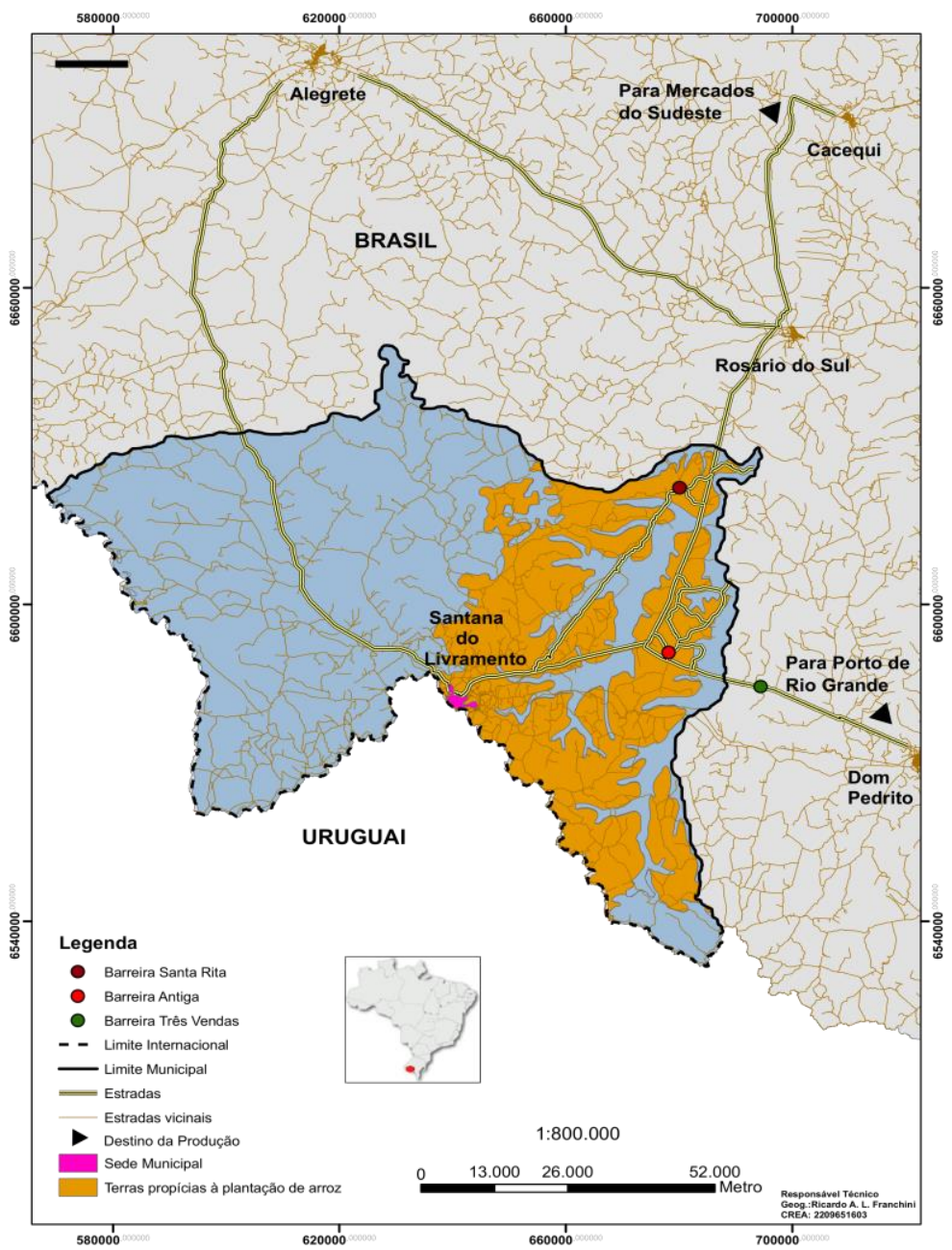

Figura 4: Sant'Ana do Livramento: localização das barreiras tributárias, das áreas produtoras de arroz e das estradas de escoamento da produção - 2012.

Elaborado por: Adriana Dorfman, Arthur Borba Colen França e Guilherme Soares, 2012. Cartografia: Ricardo A.L. Franchini. Base Cartográfica do Rio Grande do Sul, Datum: Sirgas, 2000. Projeção: UTM, geoprocessada utilizando o software de SIG (Sistema de informações geográficas) Arcgis 9.3®. 
Desacelerados os caminhões, a abordagem aos motoristas por parte dos fiscais envergando coletes identificadores fica menos difícil, auxiliada ainda pela sinalização da barreira por placas, cones e cavaletes (ver Figura 5). Entretanto, é preciso frisar que uma abordagem dessa natureza cria uma situação delicada entre fiscalizador e fiscalizado, e que, numa eventual resistência, o fiscalizado tem a vantagem de contar com um caminhão de aproximadamente 20 toneladas, enquanto o fiscalizador está totalmente exposto no meio da estrada. Segundo um fiscal: "Aqui tem que ser no peito e na raça!".

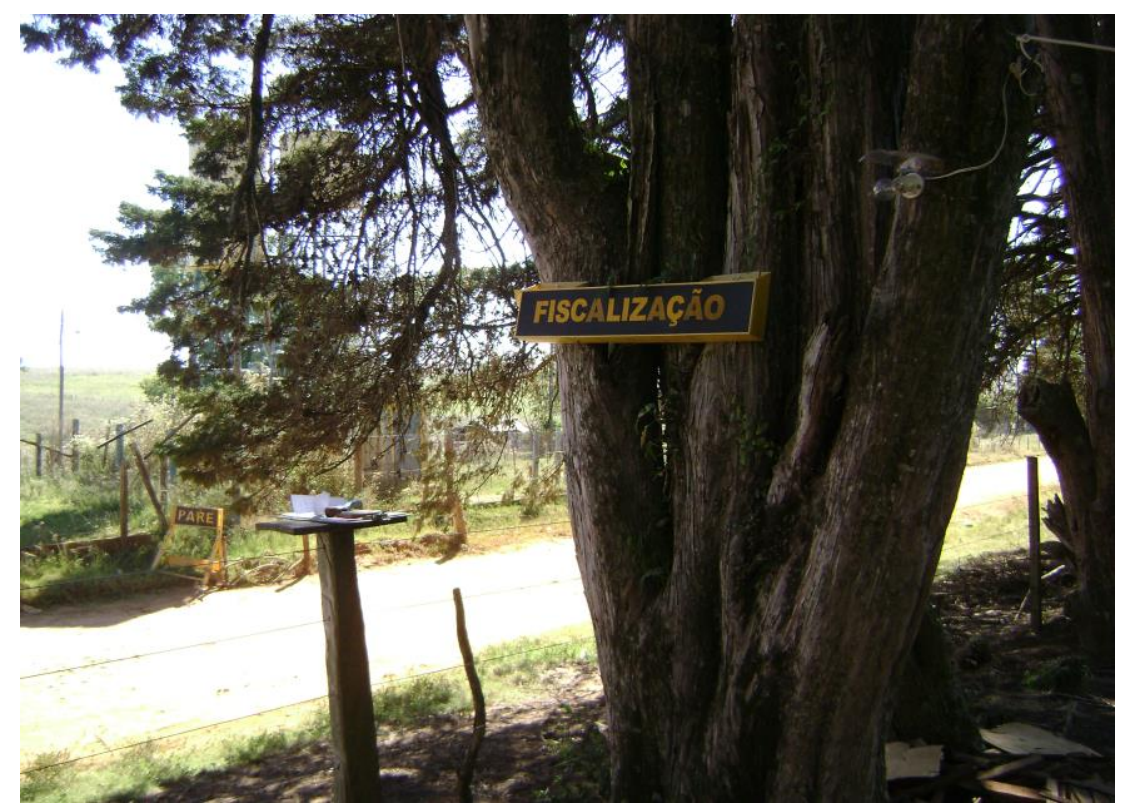

Figura 5: Posto de trabalho da barreira de Santa Rita, Sant'Ana do Livramento (RS), 31/03/2012.

Foto: Guilherme Soares.

A instalação do acampamento é de responsabilidade dos fiscais. No caso da barreira das Três Vendas, o município paga diárias e eles se encarregam de alugar uma casa onde ficarão no período da barreira fixa. No caso de Santa Rita, os fiscais devem providenciar barracas, colchões, geladeira, fogão, panelas etc (ver Figura 6). 


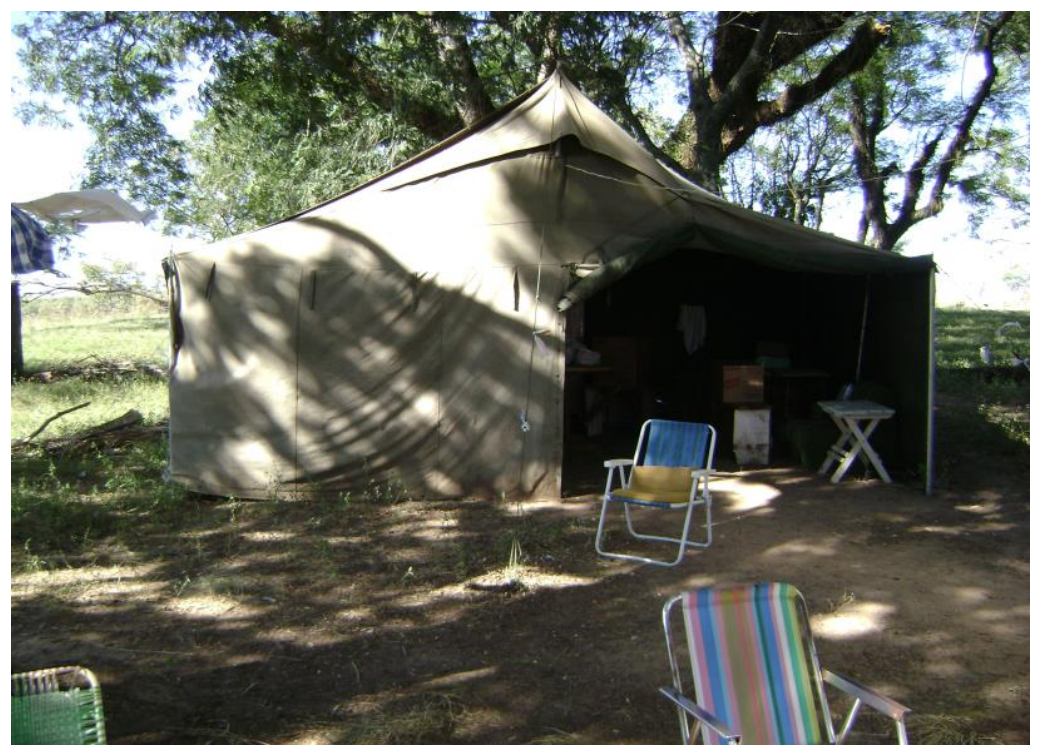

Figura 6: Cozinha da barreira de Santa Rita, Sant'Ana do Livramento (RS), 31/03/2012.

Foto: Guilherme Soares.

Essa infraestrutura difere em muito daquela descrita como apropriada por um delegado da Receita Federal do Brasil, na qual estariam presentes uma cobertura ampla e iluminada, para fiscalização sob qualquer tempo e a qualquer hora do dia; um escritório, um depósito, banheiros, cozinha e quartos para dormir, bem como um estacionamento para os veículos apreendidos (Entrevista em 12/07/2011 na 9ª RF/RFB, Curitiba).

\section{O dia-a-dia dos fiscais}

Atualmente, a Prefeitura de Sant'Ana do Livramento conta com 5 fiscais que, junto com outros funcionários municipais, que normalmente trabalham em escritórios, participam da ação. Essa mescla de funcionários aparentemente não influi na organização da barreira pois são colegas de trabalho com experiência nas tarefas burocráticas da Secretaria da Fazenda e com 15 a 30 anos de prática nessas funções. Ainda que realizada ao ar 
livre, trata-se de trabalhar com papéis. Seus pagamentos são fixos e, durante a operação, recebem o adicional das diárias.

Há uma ideia bem estabelecida entre os fiscais de que seu trabalho é muito importante para a Prefeitura e, consequentemente, para a sociedade local. Eles afirmam que a cidade não teria condições de se manter economicamente sem o imposto gerado pela fiscalização. Por outro lado, as condições em que se faz o trabalho são bastante precárias. Devido à falta de viaturas, banheiros e colchões, a necessidade de improvisar torna-se uma realidade e a "boa vizinhança" se mostra indispensável, conforme relataram os fiscais:

Fiscal A: Quando nós começamos as barreiras ali, qual foi a ideia? Quando nós chegamo na vila lá, tá, tu chega, primeira vez, né, o pessoal fica de canto, fica só te observando. O que que a gente começou, a ideia o que que era: vamos fazer a política da boa vizinhança. Então tá, montamos barreira ali, fiquemo na nossa. Passava um, a gente cumprimentava; passava um caminhão, a gente conversava com o caminhoneiro, perguntava como é que tava a estrada, se a estrada tava boa, uma reclamaçãozinha, a gente ligava pra cá. Dizia 'tchê, tem um local lá que tá atolando, não tá saindo', aí o pessoal botava um materialzinho, dava uma ajeitada. E aí o pessoal, tchê, dava um problema, por que é longe, tu viu, da vila até a faixa lá é longe, né. Aí daqui um pouco, 'tchê, uma caroninha até a faixa lá, meu guri precisa ir pra cidade' ou 'a minha esposa precisa fazer uma consulta'. 'Não tem problema, sobe aí que nós levamos'. Então a gente foi criando esse vínculo de...

Fiscal B: de amizade, pra então hoje a gente né...

Fiscal A: claro, o cara tá longe né, se precisar de alguém, de alguma coisa...

Fiscal B: assim como de repente eles precisam de nós pra dar uma carona ou fazer uma ligação pra cá pra cidade ou pra Rosário ou se comunicar com alguém, a gente também. Acontece um problema, tu visse que nós ficamos sem viatura agora lá. Antes nós tinha uma viatura em cada barreira [agora] só aquela pra fazer o rodízio, a troca, né, mas uma viatura fixa conosco ali não tem. Dá um problema, uma cobra morde um, pica um. Tu vai recorrer aonde? Nos vizinhos, na 
volta ali (Entrevista em 30/03/2012, na SEFAZ de Livramento).

$\mathrm{O}$ vínculo de amizade criado com os moradores resulta em favores como caronas até o perímetro urbano ou a utilização de chuveiros com água quente, suprindo necessidades decorrentes da falta de estrutura no acampamento. Assim, os fiscais "investidos do poder do Estado" passam a serem vistos também como bons vizinhos. E a vinculação com o Estado serve também ao pessoal de campanha, conforme relatado a seguir.

Fiscal A: Depois que termina a safra, a gente vem pra cidade. Falta muito ali a água ali do município... Aí os caras ligam pra nós, nós fazemos uma ponte com o DAE [Departamento de Águas e Esgotos]. Aí os caras não precisam vir aqui, que são cem quilômetros pros caras vir aqui pra reclamar. Os caras ligam pra nós, aí os caras vão lá e resolvem. Isso depois da barreira, que não tem mais barreira, depois que terminou a safra e nós viemos pra cidade... (Entrevista em 30/03/2012, na SEFAZ de Livramento).

Da troca de favores constrói-se uma rede baseada na reciprocidade, mas não espontânea. Por precisarem dela, dadas as carências acima discutidas, é dos fiscais que parte a iniciativa de pessoalizar as relações e embaçar a distinção público/privado. Para compreender o modo de agir dos fiscais municipais no local da barreira tributária, faz-se útil o conceito de pessoalização das relações e suas implicações. Construir relações vis-à-vis parece mais eficaz que basear-se apenas na autoridade estatal que deveria ser evidente nos fiscais, enquanto agentes do Estado. $\mathrm{O}$ raciocínio deve começar, portanto, nas razões da ineficácia dessa suposta autoridade inerente ao fiscal sobre o trânsito através desse território.

Max Weber, ao analisar o processo de formação dos Estados nacionais, concebe que o Estado é aquele que detém o monopólio legítimo da força. É preciso salientar o termo legítimo e compreender que, em um Estado, ações unilaterais de particulares seriam ilegítimas, excluindo "fazer justiça com as próprias mãos" ou utilizar-se da violência como meio de adquirir benefícios individuais. Segundo Maurício Hoelz Veiga Jr., no Brasil a autoridade dos particulares integra o tecido social de modo que o Estado não pode ser entendido como autoridade autônoma, sendo apenas um dos constituintes das redes de poder (VEIGA JR., 2011). 
Como a suposição de autoridade do Estado e seu monopólio da força não parecem ser suficientes para organizar a sociedade no Brasil, instala-se uma organização social através de redes de reciprocidade (VEIGA JR., 2011). Quer se dizer com isso que as pessoas se relacionam baseadas em possibilidades de troca, mesmo que apenas procurem garantir a subsistência ou, por outro lado, que objetivem uma reafirmação, manutenção de controle sobre o território ou os fatores produtivos. No caso em análise, as redes pessoais servem paradoxalmente para garantir a execução das atribuições estabelecidas pelo Estado. Pois de que outra forma seria possível instalar-se no meio da estrada, em campanha, sem orçamento ou estrutura, e fiscalizar a cobrança do imposto?

O que cada membro da rede espera dos outros é assimétrico, no sentido de que aqueles em posições mais favoráveis exigem mais do que fornecem e muitas vezes frustram reciprocidades de outros membros. Dessa forma, tais redes formam hierarquias, ou seja, são redes de poder. As redes de poder são construídas através da pessoalização das relações, isto é, cada membro da rede com sua reciprocidade, frustrada e assimétrica - ou não -, relaciona-se individualmente com outros e assim formam-se posições na rede. Não é um "indivíduo" genérico ou uma imposição do público sobre o privado que são os responsáveis pela formação da rede, nem são esses os melhores conceitos para compreendê-la (FOUCAULT, 1986).

No caso dos fiscais, a noção de assimetria e as posições deles na rede devem ser problematizadas, já que eles carecem de estrutura e orçamento para a execução de suas funções. A assimetria entre fiscais e comunidade, público e privado, é pequena conforme ilustra a manutenção dos contatos, mesmo depois de encerrada a safra, dessa vez por iniciativa dos moradores das Três Vendas em busca de soluções para problemas junto à administração municipal. E uma relação em certa medida similar se estabelece com os pesquisadores, recebidos com uma reserva que vai sendo substituída por proximidade sem apagamento das posições hierárquicas, na expectativa de retribuição na forma do reconhecimento da importância do trabalho dos fiscais e da diminuição das dificuldades para sua realização.

Cabe discutir os termos em que os fiscais são percebidos como autoridade pelos moradores do lugar. Segundo um interlocutor "é mais aquela coisa de impacto, né? A autoridade tá ali e o cara fica com medo e não passa" (entrevista em 20/12/2012 na SEFAZ de Livramento). A autoridade não parece depender da capacidade de empregar a violência, já 
que os fiscais não estão armados. Tampouco a aparência física dos fiscais ou seu uniforme, que se limita ao colete preto com a identificação da SEFAZ, são especialmente impressionantes. Ainda assim:

Fiscal C: Acontece que os próprios estancieiros, os próprios donos das fazendas, eles gostam dessa época da barreira porque diminui roubo, tudo, então quer dizer que tem autoridade lá na localidade, tem, entendeu? Que o pessoal ladrão não sabe o que é que tem ali, então diminui.

Pesquisador: É que não é normal, aí vai...

Fiscal C: Claro. Por isso aí, pra eles adianta bastante isso aí, mesmo tendo pouca segurança pra nós, a gente acaba dando segurança pro...

Fiscal B: só a presença, né... (Entrevista em 30/03/2012 na SEFAZ de Livramento).

Depreende-se que um tipo específico de morador local, o produtor rural, vê com bons olhos a instalação das barreiras cuja autoridade advém de sua condição de operacionalização do controle estatal, de materialização da escala estatal na localidade. Ao contrário do que se pensaria num primeiro momento, os fiscais não intimidam os estancieiros cuja produção fiscalizam e são bem-vindos, porque representam a autoridade, metem medo, dão segurança contra o ataque de eventuais abigeatários. Lembremos a afirmativa do fiscal, citada no início deste texto, de que a "barreira fixa não pega ninguém", para concluir que, para os fiscalizados, trata-se de legalizar sua produção, permitindo sua circulação no mercado nacional, com uma tolerância de até $1 / 3$ da safra ("mais que isso eles não sonegam, porque aí fica complicado"). Na rede de poder, o fiscal dá mais segurança do que tem.

Além das dificuldades logísticas, há o risco de ser mal interpretado por aqueles que passam e confundem a barreira fixa com a estratégica. Nas palavras dos informantes:

Fiscal B: pra nós que trabalhamos assim como a gente trabalha em barreira, porque assim, nós tamos ali, especificamente pra que? Pra situação do arroz e da soja, né. Mas é uma barreira. Tu sabe que em barreira tu pode enfrentar qualquer coisa. Assim como passa o caminhoneiro ali transportando o produto dele, da lavoura...

Fiscal A: Passa contrabando... 
Fiscal B: Passa contrabando, pode passar qualquer coisa ali. Ou daqui um pouco os caras até pra tentar nos intimidar, né... Fiscal A: E tu não sabe qual vai ser a reação do cara. Tu não sabe a reação do cara que tá ali. O cara pode ser cancheiro, vem com contrabando e passa, te cumprimenta 'aí, não sei o que', te mostra a nota fria. Mas daqui a pouco tu pega um apavorado e tu não sabe qual é a reação do cara. O cara vem com a...

Pesquisador: sim, pode tocar por cima.

Fiscal B: claro. Ele vem com a com a carga emocional já abalada, né (Entrevista em 30/03/2012, na SEFAZ de Livramento).

A proximidade da fronteira surge como fonte de perigo na operação dos fiscais. Os crimes fronteiriços - passagem de mercadorias, drogas, armas, transporte de ouro e divisas, exportações sem recolhimento de impostos - introduzem riscos no trabalho. Também é a condição fronteiriça que justifica a elevação do efetivo policial de diferentes órgãos na região.

\section{As relações com outros órgãos de policiamento}

Ainda que os orçamentos municipais escassos sejam recorrentemente apontados como um problema para a organização e o bom funcionamento das barreiras fixas, a relação com outros órgãos policiais parece ser muito relevante nessa rede de poder. A presença ou ausência de outro órgão na barreira fixa influi no poder dos fiscais e, consequentemente, nas assimetrias entre autoridades e comunidade, implicando controle sobre outras práticas, intimidando a comunidade local, os caminhoneiros e os passadores. Quando um órgão de policiamento está presente, como a Brigada Militar (a polícia militar gaúcha), por exemplo, os fiscais municipais se situam em um ponto mais baixo da hierarquia, sujeitando-se à pressão desses outros policiais na rede. Por outro lado, pessoal armado aumenta a segurança dos fiscais municipais diante de contraventores.

Cabe perguntar, então, como os fiscais se situam na rede de poder ampliada. E para responder a essa questão, partimos dos relatos sobre operações realizadas na área urbana de Livramento. Na cidade é de praxe que em operações de médio e grande porte, os fiscais atuem em conjunto com a Brigada Militar, a Polícia Civil, a Polícia Rodoviária, a Receita e a 
Polícia Federais. Essa relação tem como objetivo aumentar a eficiência das operações e o controle da corrupção, como relatam esses dois fiscais:

Fiscal A: A fiscalização vai sair e fazer uma barreira... a gente sempre procura trabalhar com a Brigada ou com a Polícia Civil e até com a Polícia Federal a gente várias vezes já trabalhou. A gente juntando dois ou três órgãos, evita o problema do cara tentar subornar alguém ou tentar aliviar. Então, de repente foge da nossa alçada e cai na da Brigada, foge da [competência] da Brigada e cai na nossa. Porque às vezes a Brigada não tem a competência, nem a Polícia tem a competência de entrar nos estabelecimentos pra fiscalizar sem uma ordem judicial. E nós podemos.

Fiscal B: A gente usa o argumento que tá no código de postura do artigo 171, que até parece estranho, que nos permite isso, que a Polícia nos acompanhe, mas exclusivamente pra fazer a nossa segurança, a nossa integridade física. Se for a Polícia Federal, a mesma coisa, se for a Rodoviária, a mesma coisa. Cada um na sua competência. Depois de achar o ilícito a gente repassa pra eles, se for o caso. (...) por incrível que pareça, é o município que, digamos, que tem o menor poder, mas tem o maior acesso. Nós temos acesso a qualquer tipo de comércio, então a gente aproveita essa oportunidade e usa todo o poder que se pode usar. (Entrevista em 20/12/2011 na SEFAZ de Livramento).

Ainda que haja ganho de segurança por parte de uns e de trânsito por parte de outros, as atividades integradas podem gerar atritos. O conflito entre órgãos de segurança pública frustra algumas operações e torna mais difícil a relação entre os agentes (brigadianos, policiais civis, fiscais municipais etc.), em que o coleguismo não inclui membros de outras forças policiais. $\mathrm{O}$ depoimento a seguir sintetiza esse conflito.

Fiscal B: Armaram uma situação pra ele (fiscal A) e no fim ele foi preso porque ele estava armado e o porte dele estava vencido e aí ele foi preso pela Brigada Militar. Aí respondeu processo, se incomodou...

Fiscal A: Mas hoje eu lavo minhas mãos. Trabalho com eles (brigadianos), mas assim... na ponta da faca! Se um pisar fora 
da linha eu denuncio, seja a autoridade que for. Hoje pra mim, eu digo pra eles, trato eles que nem cachorro. Não são mais meus colegas. (Entrevista em 20/12/2011 na SEFAZ de Livramento).

Tratava-se de uma relação mantida por interesse e necessidade, com o fim de improvisar para atalhar ou até mesmo burlar os processos legais (MUNIZ e PAES-MACHADO, 2010). Assim, a ação policial e fiscal mais eficiente nem sempre funciona a favor dos fiscais, que passam a situar-se no lado inferior das relações hierárquicas e assimétricas ("é o município que tem o menor poder") no meio do caminho entre a comunidade local e a Brigada, por exemplo. Mas o coleguismo parece ser circunstancial, pois o fato narra o rompimento de uma relação de interesse mútuo, a qual os brigadianos ganhavam acesso a determinados locais que, por lei, lhes seriam vedados, ao mesmo tempo em que os fiscais ganhavam segurança. Observe-se ainda a associação entre escala local; maior trânsito e melhor conhecimento do lugar; e menor poder dos respectivos agentes.

A fronteira estatal adiciona outros elementos ao contexto. Sendo um lugar onde se comunica eloquentemente a territorialidade estatal - através de bandeiras, controles, guarnições -, entram em cena Polícia e Receita Federais e o Exército Brasileiro. Como relata o informante:

Fiscal B: Agora mesmo, são oitenta camelôs ali, mas devem ter cento e quarenta ali. Aí deram uma missão pra nós, nós somos cinco fiscais e três colegas que estão ali que não são fiscais e estão nos dando um suporte ali dentro. Que condições nós vamos ter, nós, cinco fiscais, de tomar conta de cento e quarenta camelôs? Em cima da linha divisória. Aí quando houve, se montou essa operação aí, tinham 87 policiais federais, 38 policiais da Brigada Militar, não sei quantos agentes da Receita Federal, não sei quantos policiais de Rivera pra fazer uma operação. Pra organizar eles. Aí deixaram essa bomba, botaram oitenta contrabandistas ali legalizados, porque estão legalizados, hoje são microempresários, pra nós cinco tomar conta deles ali. Agora, quando foi preciso, eles botarem o poder ali, eles montaram um aparato de guerra (Entrevista em 20/12/2011 na SEFAZ de Livramento). 
Mais de 100 agentes de diferentes órgãos "botaram o poder ali", mas deixaram a manutenção da ordem na mão dos escassos funcionários municipais na forma de uma "bomba", a gestão de 80 (ou 140) camelôs sobre o limite internacional, no dito Bagashopping da Praça dos Cachorros. Note-se o emprego do termo contrabandista, nada usual na fronteira, aqui usado para marcar, diante do conflito expresso, a criminalização do comércio transfronteiriço (DORFMAN, 2009).

Neste trecho, pode-se notar outro aspecto da relação dos fiscais com a comunidade local. Há muita diferença entre chegar, controlar e partir, quando comparado às ações possíveis aos locais. Pois os fiscais municipais informam que:

Fiscal A: Depois quando estava terminando a força tarefa [combatendo o abigeato, em 2004] nós conversando "é uma burrice o que a gente fez!". Pra que é feito uma força tarefa? Justamente pras autoridades virem pra cá fazerem o que tiver que fazer sem medo de represálias e depois vão embora, e nós ficamos... Não tem como pedir transferência porque é do município. Do estado até pode o cara ficar um tempo aí, se queimou e vai embora, pede pra ir pra outro município. E é normal funcionários de outras repartições fiscalizadoras pedirem a transferência em fim de carreira. Vão pra outro lugar e lá ninguém conhece eles, chegam lá, como estão em fim de carreira já não vão ficar queimados e ficam tranquilos. A gente não pode fazer, a gente não é omisso, mas também não pode dar a cara a tapa. Não dá pra botar a cara na vitrine. Fiscal B: A gente já botou muito a cara a tapa, a gente já se envolveu muito. A autoridade é grande, então a gente não pode se envolver com isso aí, temos família. (Entrevista em 20/12/2011 na SEFAZ de Livramento).

As relações de vizinhança fazem com que os fiscais abram mão da autoridade pressuposta por sua função de pessoal do município, sob pena de represálias que podem atingi-los ou as suas famílias. Aí não se trata do risco representado por um afoito, "um apavorado com a carga emocional abalada". Trata-se dos poderosos do lugar ou do "pessoal ladrão mais cancheiro", bem ciente das normas do lugar, das redes de poder que pressupõem a tolerância a certas práticas criminalizadas noutras escalas geográficas (DORFMAN, 2009). 


\section{Considerações finais}

A "fronteira como método" mostra-nos a complexa territorialidade do Estado que pode ser vislumbrada através do exame de uma operação trivial e periférica. As redes e relações de poder experimentadas pelos fiscais municipais reposicionam a análise, enquadrando diferentes agentes nesse sítio, situação e condição específicos. Através da oscilação entre Estado e caso particular, esperamos ter revelado nexos generalizáveis.

Dentre as muitas questões a serem exploradas no quadro apresentado, recuperamos a recorrente metaforização da sociedade no espaço, ou do Estado no território, que pode ser encontrada em afirmativas como "o município é o mais fraco", na qual se observa a associação entre escala local, melhor conhecimento e trânsito no lugar e menor poder dos respectivos agentes.

Mas o território não é apenas metáfora, ele condiciona as ações possíveis aos fiscais - que não quererão transgredir as normas locais, diferentemente de agentes de forças estaduais e federais e com mobilidade na escala nacional. A fronteira e a identidade com a população local aparecem também como condicionantes.

Entre as principais estratégias espaciais inclui-se a escolha do lugar de montagem da barreira, que se mostra apropriado por sua situação de nó relevante nos fluxos de escoamento da produção e também por ser um sítio com qualidades básicas de habitação pelos fiscais, como sombra e proximidade a um povoado. A opção por uma barreira fixa permite ao mesmo tempo controlar impostos e legalizar a produção do município, sem tensionar excessivamente a relação fiscal-fiscalizado. Essa materialização tem como efeito secundário comunicar sobre o controle estatal, diminuindo ilícitos que não são objetos diretos da barreira fixa.

Por fim, cabe discutir as afirmativas que ora apontam para a pessoalização, ora para a impessoalização das relações entre o pessoal do município, o pessoal ladrão, os moradores, os fazendeiros, os caminhoneiros, policiais de outras alçadas, "os que têm medo" e "aqueles que não têm".

Afirmamos inicialmente que a barreira fixa é uma estratégia espacial que permite impessoalizar certas normas estabelecidas pelo interesse de alguns grupos sociais, estabilizadas nos regimes tributários vigentes sobre o território e fiscalizadas por funcionários do Estado. Em outras palavras, a 
montagem da barreira fixa desloca a agência dos grupos da lei tributária e de seus fiscais e a reifica num objeto espacial. Num segundo momento, afirmamos que os fiscais responsáveis pela montagem da barreira pessoalizam as relações com os moradores da vizinhança. Trata-se de uma estratégia para executar suas funções, uma vez que as estrutura montada pela SEFAZ é considerada precária, sendo necessário reforça-la pela rede de poder (nem tão assimétrica como pareceria num primeiro momento) tecida por fiscais e moradores da vizinhança.

Cabe notar que discutimos primeiramente a territorialidade como materialização das relações de poder e, na sequencia, abordamos as relações de poder num lugar específico. Trata-se, portanto, de uma oscilação entre a análise das materialidades e dos agentes que as produzem. Ainda que seja um objeto, a barreira é montada e mantida pelas ações dos fiscais que, entretanto, não possuem poder suficiente para realizar essa impessoalização - a barreira - sem recurso à pessoalização.

\section{Bibliografia}

ALLIÈS, P. (1980) L'invention du territoire. Grenoble: PUG.

COPSTEIN, G. et al. (1989) Aglomerações urbanas fronteiriças. In: Encuentro de Geógrafos de America Latina, 2. Montevidéu: UGAL. pp. 223-231.

DAMATTA, R. (1978) O ofício do Etnólogo, ou como ter o "Anthropological Blues". In: NUNES, E. (org.). A Aventura Sociológica. Rio de Janeiro: Zahar.

DORFMAN, A. (1992) Sistemas escalares em Geografia. Boletim Gaúcho de Geografia, v. 19, n.1. Disponível em: <http://seer.ufrgs.br/index.php/bgg/article/view/38013/24496>. Acessado em: 05 mar. 2014.

. (2007) Fronteira e contrabando em Santana do Livramento (BR) - Rivera (UY). Boletim Gaúcho de Geografia, v. 32, n. 1.

- (2009) Contrabandistas na Fronteira Gaúcha: escalas geográficas e representações textuais. Tese (Doutorado em Geografia), Florianópolis. Disponível em: <http://Www.tede.ufsc.br/teses/PGCN0367T.pdf.> 
DORFMAN, A.; PRYTOLUK, M. B.; SEBASTIÃO, R. M. (2011) Estratégias de pesquisa sobre o contrabando. Revista GeoPantanal, v. 6. pp. 33-46.

FOUCAULT, M. (1986) Microfísica do Poder. Rio de Janeiro: Graal.

FRANCK, C. J. et al. (2011) Estudo econômico para a implantação de uma unidade de beneficiamento de arroz no município de Rio Grande - RS. $X X$ Congresso de Iniciação Científica, III Mostra Científica UFPel. 2011. Disponível em <http://www.ufpel.edu.br/cic/2011/anais/pdf/EN/EN_00290.pdf. Acessado 14 mai. 2012.

MEZZADRA, S.; NEILSON, B. (2008) Border as Method, or, the Multiplication of Labor. Disponível em: http://eipcp.net/transversal/0608/mezzadraneilson/en/print Acessado em: 14 mai. 2012.

MUNIZ, J. de O.; PAES-MACHADO, E. (2010) Polícia para quem precisa de polícia: contribuições aos estudos sobre policiamento. Caderno CRH, Salvador, v. 23, n. 60, set./dez. p. 437-447.

PÉBAYLE, R. (1978) Frontières et espaces frontaliers du Brésil meridional. Cahiers des Amériques Latines (18), $2^{\circ}$ semestre. p.33-45.

RACINE, J. B.; RAFFESTIN, C.; RUFFY, V. (1983) Escala e ação: contribuições para compreensão do mecanismo de escalas na prática da geografia. Revista Brasileira de Geografia, n. 45 (1). Rio de Janeiro: IBGE. p. 123-135.

RAFFESTIN, C.. (1993) Por uma Geografia do Poder. São Paulo: Ática.

SACK, Robert David. (1986) Human Territoriality: its theory and its history. Cambridge: CUP.

SMART, A.; LIN, G. C. S. (2014) Capitalismos locais, cidadania local e translocalidade: mudança escalar de baixo para cima na Região do Delta do Rio da Pérolas, China. Boletim Gaúcho de Geografia, v. 41, n. 1, jan. Disponível em: <http://seer.ufrgs.br/index.php/bgg/article/view/43811>. Acesso em: 26 fev. 2014.

VEIGA JR., M. H. (2011) Violência e pessoalização numa sequência sociológica. XV Congresso Brasileiro de Sociologia, Curitiba. 
GEOgraphia - Ano. 17 - №33 - 2015

Data de submissão: 28/08/2014.

Data de aceite: 01/02/2015. 